\title{
EL EPISODIO DEL LIBRO \\ FLOR DE LOS AFORISMOS PEREGRINOS \\ EN EL PERSILES (IV, L): \\ TRADICIONES CULTURALES, CONTEXTO HISTÓRICO \\ Y CARÁCTER LÚDICO
}

El Persiles, historia polifacética, se presenta como una larga peregrinación tanto espacial y temporal como narrativa, cuyo punto de llegada es la Ciudad Eterna. Hacia el final de la obra, en los albores del libro IV, Auristela y Periandro, así como los demás peregrinos que los acompañan, llegan "una jornada antes de Roma y, en un mesón, adonde siempre les solía acontecer maravillas, les aconteció ésta..." (IV, 1, p. 630)1.

En síntesis, recuérdese que sale a su encuentro un gallardo peregrino con un cartapacio y unas escribanías quien, en lengua castellana, no sólo se define como peregrino sino que añade otras características sobre su persona, que comentaremos posteriormente.

Este hombre desea publicar un libro titulado Flor de aforismos peregrinos -jugando con las dos acepciones del último vocablo-, constituido a costa ajena, ya que ha de componerse de los dichos agudos o de las sentencias del mismo tipo, que las personas encontradas en el camino, cuya presencia muestra ser "de ingenio y de prendas" -según dice- han escrito y firmado. Así ha recogido ya más de trescientos aforismos y piensa ganar mucho dinero con ellos.

Salen pues a relucir varios aforismos hasta llegar a la sentencia apuntada por un zapatero de Tordesillas, que ultima la serie.

Dicho episodio, que aparece como una manera de entretener a los peregrinos, y más allá a los lectores, aprovechando el

1 Utilizamos la edición de Miguel de Cervantes, Los trabajos de Persiles y Sigismunda I, ed. C. Romero, $2^{\text {a }}$ ed., Cátedra, Madrid, 2002. 
descanso de fin de jornada, a la usanza de Timoneda ${ }^{2}$, hunde sus raíces en diversas tradiciones culturales, pero va unido, asimismo, a un ambiente lúdico que invierte la aparente gravedad del suceso, a un contexto histórico relacionado con la actuación de un personaje célebre de la época.

Son pues estos aspectos los que deseamos evocar en el presente trabajo.

Antes de ir más allá, es necesario tener presente que el episodio se verifica en el ámbito de un mesón, el cual corresponde a la venta rural. Es decir que se trata de un lugar de paso, lugar abierto, que favorece los encuentros e intercambios, en que todo puede ocurrir, especialmente lo más extraño o prodigioso $^{3}$. Es lo que pasa varias veces en el Quijote, en las ventas ${ }^{4}$, es lo que pasa, asimismo, en diversas ocasiones en los mesones del Persiles. De ahí que en este caso, el narrador utilice el término "maravilla" y generalice el proceso a las posadas del texto ya que en ellas -indica-, "les solía acontecer".

Procedimiento narrativo, reivindicado como tal, pero el empleo del vocablo "maravilla" viene a ser significativo dado que señala Covarrubias, en su Tesoro de 1611: "maravilla: cosa que causa admiración... por ser extraordinaria" . La maravilla remite en efecto al orden natural, por oposición al milagro (que tiene la misma raíz y refiere al ámbito sobrenatural). No obstante, lo maravilloso pertenece al campo semántico de lo "prodigioso", lo que implica una concepción de la realidad concebida como un jeroglífico que es preciso descifrar ${ }^{6}$. Es

${ }^{2}$ Pensamos, claro está, en El Sobremesa y Alivio de caminantes. Véase la ed. de M. P. Cuartero y M. Chevalier, Espasa Calpe, Madrid, 1989.

${ }^{3}$ Sobre el papel desempeñado por las ventas en los relatos del Siglo de Oro, véase MoniQue Joly, La bourle et son interprétation. Recherches sur le passage de la facétie au roman (XVI ${ }^{e}-X V I I^{e}$ siècles), Atelier National de Reproduction des Thèses, Lille, 1982, pp. 505 ss.

4 Acerca de la importancia de las ventas en el Quijote, véase Augustin Redondo, Otra manera de leer el "Quijote". Historia, tradiciones culturales y literatura, $2^{\text {a }}$ ed., Castalia, Madrid, 1998, pp. 150 ss., 297 ss., etc.

5 Sebastián de Covarrubias, Tesoro de la lengua castellana o española, Horta, Barcelona, 1943, p. 789a.

${ }^{6}$ De manera significativa, véanse sobre este universo las consideraciones, hacia 1570, de ANTONIO DE TORQuemada, El jardín de flores curiosas, ed. G. Allegra, Castalia, Madrid, 1982. Acerca del doble campo semántico evocado, véase Augustin Redondo, "Los prodigios en las relaciones de sucesos del Siglo de Oro", en Les “relaciones de sucesos” en Espagne (1500-1750), 
pues una incitación por parte del escritor a superar lo que aparece a primera vista, es una manera muy cervantina de solicitar la colaboración del lector para poder llegar al meollo del texto. Es lo que vamos a intentar hacer.

Cuando Cervantes está escribiendo este trozo, probablemente después de 1613, el aforismo, unido tanto al arte verbal como a la emblemática al modo de Alciato ${ }^{7}$, está irrumpiendo en el espacio político, unido al tacitismo, y ello gracias a Baltasar Álamos de Barrientos, quien publica en Madrid, en 1614, su Tácito español ilustrado con aforismos ${ }^{8}$.

Recuérdese, sin embargo, que el aforismo pertenece fundamentalmente en un principio al campo de la medicina. Es un término griego utilizado por los médicos de la Antigüedad para, según dice Galeno y transcribe Covarrubias, remitir a "cierto género de doctrina y método que, con breves y sucintas palabras, circunscrive y ciñe todas las propiedades de las cosas", dando el lexicógrafo como ejemplo los Aforismos de Hipócrates (los más conocidos) y también los del astrónomo/astrólogo Ptolomeo en su Centiloquio ${ }^{9}$.

Durante la Edad Media, la voz quedó reducida al ámbito médico antiguo, con referencia sobre todo a Hipócrates ${ }^{10}$. Cuando se trataba de recoger un saber general de orientación moral, presentado de modo conciso, se hablaba de sentencias. Con la explosión de las formas breves en el siglo Xvi, y dejando de lado la sabiduría de los Adagios, recopilados por Erasmo, así

eds. María Cruz García de Enterría et al., Publications de la SorbonneUniversidad de Alcalá, Paris-Alcalá de Henares, 1996, pp. 287-303, y más directamente, pp. 288-290.

7 Sabido es que la obra de Alciato tuvo diversas ediciones en el siglo Xvi. Véase Alciato, Emblemas, ed. S. Sebastián, Akal, Madrid, 1985.

${ }^{8}$ Hemos manejado la ed. princeps: Tácito español ilustrado con Aforismos, por Don Baltasar Álamos de Barrientos. Dirigido a Don Francisco Gómez de Sandoval y Rojas, Duque de Lerma, Marqués de Denia Ėc., Luis Sánchez y Juan Hasrey, Madrid, 1614, BNE: R. 17058. Álamos de Barrientos traduce los Anales, la Historia, el Libro de las costumbres de los Alemanes y La vida de Julio Agrícola. Luego, al final de la obra, figuran los aforismos, clasificados por temas ("Abogados", "aborrecer", etc.). Hemos utilizado esta edición y citamos por ella. Puede verse también la ed. moderna: Aforismos al Tácito español, ed. J. A. FernándezSantamaría, Centro de Estudios Constitucionales, Madrid, 1987, 2 ts.

${ }^{9}$ Véase Tesoro, p. 97 a.

10 Véase María Teresa Herrera (dir.), Diccionario español de textos médicos antiguos, Arco/Libros, Madrid, 1996, 2 ts. En la entrada "Aforismo" aparecen constantemente referencias a Hipócrate (Ypocras) y algunas veces, a Galeno. 
como la que encerraban los refranes de carácter popular, aparecen otros términos para designar un saber general presentado brevemente, tales como apotegma, máxima, etc. ${ }^{11}$ Verdad es que la difusión renacentista de los "dichos y hechos" de los antiguos, siguiendo la pauta de Plutarco y Valerio Máximo, ha provocado el florecer de esas formas breves que podían cuajar en dichos agudos y en sentencias, mezclados con algunos hechos célebres, tal como lo ilustra la famosa Floresta española de Melchor de Santa Cruz, publicada en $1574^{12}$.

Ya a finales del siglo XVI y principios del siglo XVII, la difusión de Justo Lipsio, muy admirado, en particular por Quevedo, tanto por su senequismo y tacitismo como por su prosa aguda y concisa -uno de los antecedentes del arte practicado por Baltasar Gracián ${ }^{13}$ - viene a ser un modelo para muchos escritores de esos años ${ }^{14}$. Es que Tácito se había impuesto como

11 Sobre el particular, véase el título revelador de la obra de Melchor de Santa Cruz de Dueñas, Floresta española de Apothegmas o sentencias, sabia y graciosamente dichas de algunos españoles, Francisco de Guzmán, Toledo, 1574. Véase, asimismo, la introducción de M. P. Cuartero y M. Chevalier (pp. xxix ss.) a su ed., que es la que utilizamos: Crítica, Barcelona, 1997. Por otra parte, y de manera general, véase Andrea Herrán SANtiago, "La prosa epistolar y aforística del siglo xvi", en Miguel Ariza et al., Actas del II Congreso Internacional de Historia de la Lengua, Pabellón de España, Madrid, 1992, t. 2, pp. 675-690.

${ }^{12}$ Véase nota precedente.

13 Al respecto, véase Aurora Egido, Las caras de la prudencia y Baltasar Gracián, Castalia, Madrid, 2000, pp. 150 ss.

14 Véase Los seys libros de las Políticas o doctrina civil de Iusto Lipsio para el gobierno del Reyno o Principado. Traduzidos de lengua latina en castellano por Bernardino de Mendoça. Dirigido a la Nobleza Española, Imprenta Real, Madrid, 1604, BNE: 3/13170. La obra lleva un prólogo del traductor, Bernardino de Mendoza, y encierra diversas sentencias de varios autores que subrayan el laconismo ilustrado por el texto. Acerca de Justo Lipsio y de su influencia en España, pueden verse José A. Fernández-Santamaría, Razón de estado y política en el pensamiento español del Barroco (1595-1640), Centro de Estudios Constitucionales, Madrid, 1986, pp. 83-85, 241-243, etc.; Elena Cantarino Suñer, "Justo Lipsio en España. Humanismo, Neoestoicismo y Tacitismo", en Hacia un nuevo inventario de la ciencia española. IV Jornadas de Hispanismo Filosófico, eds. G. Capellán de Miguel y X. Agenjo Bullón, Sociedad Menéndez Pelayo, Santander, 2000, pp. 77-84. Sobre el universo de Lipsio y su relación con los españoles, véase M. Laureys (ed.), The world of Justus Lipsius. A contribution towards in intelectual biography, Bulletin de l'Institut Historique Belge de Rome, Bruxelles-Rome, 1998; Epistolario de Justo Lipsio y los Españoles (1577-1606), $2^{\text {a }}$ ed., ed. A. Ramirez, Castalia-Washington University Press, Madrid-Saint Louis, 1967. Con respecto a los trabajos de Lipsio sobre Táci- 
un dechado porque su pensamiento (fundamentado en una utilización de la Historia que establece un prudencialismo) se moldea en frases sentenciosas, las cuales permiten delinear un racionalismo de comportamiento a base de experiencias históricas. Esas normas son directamente utilizables por los gobernantes y más allá, por los particulares ${ }^{15}$. De ahí la gran difusión del tacitismo vertido en aforismos.

Es el propio Álamos de Barrientos quien, en uno de los preliminares de su obra, titulado Discurso para inteligencia de los Aforismos, uso y provecho dellos, señala, al principio del texto, que ha querido "sacar, como buen destilador, el espíritu y quinta essencia de la historia de Tácito, reduzido a unas reglas o conclusiones generales, avisos y advertencias de las acciones humanas". Al final de dicho texto, añade: "Quise usar deste nombre de Aforismos, aunque pudiera del de reglas, sentencias o conclusiones". En el mismo Discurso..., confiere el estatuto de ciencia a la sabiduría tacitista ("yo avré dado principio a esta manera de ciencia en nuestra nación") y la equipara con la medicina y la astrología, "ciencias" que Hipócrates y Ptolomeo habían ilustrado, dándoles un nuevo impacto gracias a sus aforismos, que se apoyaban en una experiencia personal. La finalidad perseguida, dice Álamos de Barrientos, es parecida a la que buscaban los dos clásicos citados ya que "es propio de los hombre prudentes y bien experimentados notar y ponderar las cosas pasadas para entender bien las presentes y hacer juyzio y discurso de las venideras". Por ello, el término "aforismo" puede utilizarse en el intento similar llevado a cabo con esta nueva ciencia. Empleado así, el vocablo aparece como una novedad (nótese que

to, véase José Ruysschaert, Juste Lipse et les "Annales" de Tacite. Une méthode de critique textuelle au XVI siècle, Publications de l'Université, Louvain, 1949.

15 Véase Francisco Sanmartí-Boncompte, Tácito en España, CSIC, Barcelona, 1951; EnriQue Tierno Galván, "El tacitismo en las doctrinas políticas del Siglo de Oro español”, Escritos (1950-1960), Tecnos, Madrid, 1971, pp. 11-93; José Antonio Maravall, "La corriente doctrinal del tacitismo político en España", Estudios de Historia del Pensamiento Español. Serie tercera. Siglo XVII, Cultura Hispánica, Madrid, 1975, pp. 75-105; J. A. FernándezSantamaría, Razón de estado y política..., pp. 163-172, especialmente; BEATRIz Antón Martínez, El tacitismo del siglo XVII: proceso de "receptio", Universidad, Valladolid, 1992; André Joucla-RuAu, Le tacitisme de Saavedra Fajardo, Éds. Hispaniques, Paris, 1977; María Teresa Cid Vázquez, Tacitismo y razón de estado en los "Comentarios Políticos" de Juan Alfonso Lancina, Universidad Complutense, Madrid, 2001. 
en 1611, en su Tesoro, Covarrubias no menciona esta acepción de la palabra).

Sin embargo, por lo que hace a los escritores españoles, el primero que utiliza el término "aforismo", fuera del campo primitivo $^{16}$, es el antiguo Secretario de Estado de Felipe II, el exilado Antonio Pérez, tacitista y amigo de Álamos de Barrien$\operatorname{tos}^{17}$. Ya volveremos posteriormente sobre el tema.

En cuanto a los aforismos del trozo del Persiles que analizamos, Cervantes se sirve del vocablo con el sentido nuevo. En efecto, se trata, según la terminología que emplea el recolector, de algún dicho agudo o de alguna sentencia, también aguda, ambos vinculados a una persona, aunque estas características encajen más dentro de la tradición de las sententiae pues la mayoría versan sobre la honestidad de la mujer y el casamiento, que no dentro de la nueva orientación a lo Álamos de Barrientos. Aún las dos máximas relacionadas con los hombres se centran en el comportamiento del soldado y no del gobernante.

Es de advertir que las diversas máximas del texto aparecen, bajo la forma apuntada $u$ otra parecida, sea en obras morales de los antiguos, sea en la Floresta de Santa Cruz o en el Vocabulario de Correas, sea en colecciones de apotegmas (como la de Juan Rufo de 1596) o de proverbios morales (como la de Cristóbal Pérez de Herrera de 1618). Para dar sólo dos ejemplos, el aforismo escrito por Ruperta: "La hermosura que se acompaña con la honestidad es hermosura y la que no, no es más de un buen parecer" (p. 633) evoca al apotegma apuntado por Rufo: "la hermosura sin honestidad es como un jardín sin

16 Nótese que la palabra había aparecido ya en el campo religioso, dado que la había utilizado el jesuita Manuel Sá, al publicar sus Aphorismi Confessariorum ex Doctorum sententiis collecti Auctore R. P. Emmanuel Sa lusitano... (Venetiis, 1592). Este texto se publicó asimismo en España en 1600 (Luis Sánchez, Madrid) y 1601 (Pedro Madrigal, Madrid).

17 A raíz de la fuga de Antonio Pérez a Aragón y luego a Francia, Álamos de Barrientos fue apresado en 1590 y quedó en la cárcel hasta la muerte de Felipe II porque se pensó que conocía los secretos del Secretario real y no quiso testimoniar contra él. El mismo Álamos, en la dedicatoria del Tácito español al duque de Lerma, indica que redactó la obra en la cárcel y que el soberano se opuso a la publicación del texto. En el discurso "Al lector", vuelve sobre el tema, señalando que en 1594 deseó dar a la imprenta la obra. Pero, a pesar de la aprobación del licenciado Antonio de Covarrubias, se la embargó y sólo se la devolvió cuando recobró él la libertad. En sus Pedaços de Historia, en 1593 (cf. infra), Antonio Pérez dice que Álamos era muy gran amigo suyo y que lo encarcelaron porque no quiso acusarlo (pp. 87-88). 
agua, o como flores pisadas" ${ }^{18}$. Del mismo modo, Croriano indica: "Más hermoso parece el soldado muerto en la batalla que sano en la huida" (p. 632), lo que hace pensar en el proverbio inserto por Pérez de Herrera en su colección: "Ni hay más baxo deshonor / que en la guerra cobardía"19.

Sin embargo, lo que llama la atención en el pasaje cervantino es que todos esos aforismos, salidos de la pluma de personas de pro generalmente, van firmados, es decir que corresponden a una experiencia personal en la línea de la nueva orientación.

En el conjunto de máximas que figuran en este trozo del Persiles, irrumpe un aforismo tan sentencioso como los demás, de tonalidad senequista, vinculado a una experiencia personal: "No desees y serás el más rico hombre del mundo" (p. 634). A primera vista, este aforismo parece que sale, según lo indicado por el acopiador, de una "persona de ingenio y de prendas". Pero la sorpresa del lector es grande cuando descubre la firma del que ha escrito dicha máxima: "Diego de Ratos, corcovado, zapatero de viejo en Tordesillas, lugar en Castilla la Vieja, junto a Valladolid" ${ }^{20}$. Estamos frente a una paradoja, una de esas paradojas tan empleadas por los humanistas, con Erasmo a la cabeza. La óptica viene a ser la de la inversión paródica e irónica según una técnica muy utilizada en el Quijote ${ }^{21}$.

No hay que olvidar lo que representa el zapatero desde épocas muy antiguas: aparece como un personaje proteico. Por un lado, existe una tradición del remendón filósofo, como Micilo, el zapatero alegre y filósofo puesto en escena por Luciano a quien su gallo demostraba que, al no envidiar a nadie, era el ciudadano más dichoso de Atenas ${ }^{22}$. Esta tradición, de la cual

18 JUAn Rufo, Las seiscientas apotegmas y otras obras en verso, ed. A. Blecua, Espasa Calpe, Madrid, 1972, núm. 593, p. 206.

19 Cristóbal Pérez de Herrera, Proverbios morales y consejos christianos muy provechosos para concierto y espejo de la vida..., Luis Sánchez, Madrid, 1618, BNE: R.1727, núm. 301, f. 17r.

${ }^{20}$ Nótese que existían varias categorías de zapateros (de viejo; de nuevo) que formaban parte de gremios diferentes: véase Miguel Herrero García, Oficios populares en la sociedad de Lope de Vega, Castalia, Madrid, 1977, pp. 195 ss.

${ }^{21}$ Véanse de A. Redondo, Otra manera de leer el "Quijote".., pp. 148 ss., 205 ss., 232 ss., etc.; y En busca del "Quijote" desde otra orilla, Centro de Estudios Cervantinos, Alcalá de Henares, 2011, pp. 103 ss.

${ }^{22}$ Sobre el particular, véanse PAul SÉBillot, Légendes et curiosités des métiers, facs. de la $1^{\text {a }}$ ed. (1894-1895), Laffitte Reprint, Marseille, 1981, pp. 306-307; Mauritz de Meyer, Le conte populaire flamand, Academia Scientiarum Fennica, Helsinki, 1968, núm. 754, p. 88; etc. 
se hacen eco, por ejemplo, Sebastián de Horozco $^{23}$ y Cervantes en este trozo, llega hasta Ramón Pérez de Ayala quien idea a sus dos zapateros, Belarmino y Apolonio ${ }^{24}$. Asimismo, otra tradición que se remonta a la pasión de Cristo, se centra en ese zapatero que, en la calle de la Amargura, hubiera dado prisas a Jesús, insultándole y golpeándole con la horma de un zapato. Para castigarle, el mismo Cristo le hubiera condenado a errar por la superficie de la tierra hasta el día del Juicio. Esta leyenda ha dado origen al personaje del Judío errante. Éste aparece varias veces en la España del siglo XVI y en la literatura (por ejemplo en el Viaje de Turquía), bajo el nombre de Juan de Espera en Dios, lo que ha estudiado magistralmente Marcel Bataillon ${ }^{25}$. El personaje del Persiles se inserta pues en esta tradición del zapatero errante y peregrino (Juan de Espera en Dios va a Jerusalén y vuelve de allá).

Por otra parte, el zapatero ha cobrado mala fama por tener la reputación de ser engañoso y ladrón, como lo subraya un dicho recogido por Hernán Núñez y Correas: "Zapatero, gente mala" 26 y lo insinúa Covarrubias, al escribir: "Zapatero... aunque parece oficio vil, muchos han enriquezido en él” ${ }^{27}$. No extraña pues que el Licenciado Vidriera diga pestes del zapatero, así como del sastre su compadre ${ }^{28}$, y que Francisco de Quevedo los precipite a ambos entre las garras de los diablos en Los

23 Véase Sebastián de Horozco, Teatro universal de proverbios, ed. J. L. Alonso Hernández, Universidad de Salamanca-Universidad de Groningen, Salamanca, 1986, núm. 962.

${ }^{24}$ Véase Ramón Pérez de Ayala, Belarmino y Apolonio, ed. A. Amorós, Cátedra, Madrid, 1978.

25 Véase Marcel Bataillon, "Peregrinaciones españolas del judío errante”, Varia lección de clásicos castellanos, Gredos, Madrid, 1964, pp. 81-132.

26 Véanse Hernán Núñez, Refranes o proverbios en romance [1554], eds. L. Combet et al., Guillermo Blázquez, Madrid, 2001, núm. 6745; Gonzalo Correas, Vocabulario de refranes y frases proverbiales, ed. L. Combet, revisada por R. Jammes y M. Mir-Andreu, Castalia, Madrid, 2000 (como en esta edición se ha adoptado la ortografía y el orden alfabético actuales, no es necesario dar la página que corresponde a los refranes que hemos de citar).

27 S. de Covarrubias, Tesoro..., p. 394a.

28 Véase Miguel de Cervantes, El licenciado Vidriera, en Novelas ejemplares, ed. J.B. Avalle Arce, Castalia, Madrid, 1982, t. 2, p. 132. Nótese que el sastre va asociado frecuentemente al zapatero y que, en muchas de sus características y comportamientos, el uno puede sustituir al otro: cf. MAXIME Chevalier, Tipos cómicos y folklore. Siglos XVI-XVII, Edi 6, Madrid, 1982, pp. 96 ss. ("Sastres y zapateros"). 
sueños $^{29}$, etc. Por ello, el zapatero del Persiles se llama Diego de Ratos.

En efecto, Diego es lo mismo que Santiago, lo que hace pensar en otro gran lugar de peregrinación, el compostelano, de modo que Diego es el nombre que le conviene particularmente a un peregrino ${ }^{30}$. Pero el segundo elemento del apelativo se presenta como un inversor del primero pues el "rato" es el "ratón": es lo que ilustra el refrán recogido por Hernán Núñez: "De casa del gato, no va harto el rato" ${ }^{11}$ y lo que indica asimismo el sistema de concatenación, con alusión a un cuento de tradición popular, empleado en el Quijote (I, 16) para referirse a los golpes que se tributaban los diversos personajes implicados en la aventura nocturna de Maritornes, en la venta: "y así como suele decirse «el gato al rato, el rato a la cuerda, la cuerda al palo»". Y bien sabido es que el ratón y la rata roban y se comen lo que pueden alcanzar en las casas (piénsese en el episodio del arcaz viejo del Lazarillo, en el tratado segundo, cuando el joven sirve al cura de Maqueda). Por ello en el Siglo de Oro, en la lengua de germanía, las palabras "ratón" y "ratero" designaban a los ladrones de baja estofa, entre los cuales la voz pública incluía a los zapateros ${ }^{32}$. De este modo, Diego de Ratos viene a ser Diego el ladrón, siendo su nombre una especie de oxímoron. ¿No se estará sugiriendo que el aforismo no es de su cosecha? Entre burlas, ¿no se estará planteando el problema de lo que llamaríamos hoy "la propiedad intelectual", tan unida a la experiencia del propio Cervantes?

Pero hay más ${ }^{33}$. Se decía que los zapateros estiraban el cuero con los dientes para que diera más de sí, lo que les proporcio-

${ }^{29}$ Véase Francisco de Quevedo, Los sueños, ed. I. Arellano, Cátedra, Madrid, 1991, p. 101 (El sueño del juicio final) y pp. 193-194 (El sueño del infierno).

${ }^{30}$ Obsérvese, no obstante, que el nombre Diego va regido, él también, por la reversibilidad y, en contextos marcados, puede cobrar una consonancia negativa: véase A. Redondo, En busca del "Quijote”, pp. 219-220.

31 H. Núñez, Refranes..., núm. 1662.

32 Véase José Luis Alonso Hernández, Léxico del marginalismo en el Siglo de Oro, Universidad, Salamanca, 1977, pp. 658-659.

${ }^{33}$ A todo lo indicado ya, hay que añadir lo que apunta Sebastián de Horozco, al comentar el refrán: "El moço del escudero / anda un año sin çapatos / después muele al çapatero": "El moço del escudero / que anda un año sin çapatos / después si güele dinero / muele y mata al çapatero / si se detiene dos ratos" (Teatro universal de proverbios, núm. 962). Por fin, nótese que en las Cartas de Antonio Pérez (cf. infra) la expresión "y a cabo de rato" vuelve con alguna frecuencia. Utilizando el ambiente lúdico evocado yjugando con 
naba mayores ganancias. De ahí que en una profecía burlesca, de finales del siglo xv, se indique: "Saldrán los zapateros... estirando las suelas con los dientes, y harán de una, dos" ${ }^{34}$. A ello se refiere un refrán apuntado por Correas: "Ni zapatero sin dientes, ni escudero sin parientes" ${ }^{35}$. A este respecto, hay que tener presente que viejas creencias mágicas unían los dientes con el ratón y, en el sistema del don y contra-don estudiado por Marcel Mauss ${ }^{36}$, estas creencias ocasionaban la entrega a un ratón del diente que se les caía a los niños, tirándolo al tejado por el que circulaba el roedor o depositándolo a veces en el agujero en que se refugiaba. Así, la ratita le traía al niño una moneda o un nuevo diente tan fuerte como el de esos animales. Dichas creencias han llegado hasta nuestros días, como lo atestigua la presencia del célebre Ratón Pérez al cual los niños españoles siguen entregando los dientes caídos ${ }^{37}$.

Así que Diego de Ratos es también Diego de los dientes, de esos dientes utilizados para robar parte de la piel empleada como material. Otra vez, Diego de Ratos aparece como un ladrón ¿de aforismos? La orientación lúdica se manifiesta pues de otro modo.

Hay que añadir que el zapatero (lo mismo pasa con el sastre), inclinado constantemente sobre su labor, es evocado muchas veces como un corcovado, lo que ha dejado bastantes rastros folclóricos ${ }^{38}$. Al adolecer de una giba, defecto físico considerado como señal de un defecto moral, la mala fama del zapatero no podía sino hallarse acentuada, dado que es muy posterior el beneficio que se podía sacar al tocar la corcova. Recuérdese, para dar sólo un ejemplo, todas las sátiras que salieron en el siglo XVII contra ese pobre corcovado que fue el dramaturgo Juan Ruiz de Alarcón ${ }^{39}$.

la paronomasia (véase nota 40 y texto correspondiente), Cervantes hubiera podido crear al personaje de Diego de Ratos: "y a cabo de rato = Iacobo de rato = Diego de Ratos".

34 Véase M. Chevalier, Tipos cómicos..., p. 97.

35 G. Correas, Vocabulario de refranes...

36 Sociologie et anthropologie, Presses Universitaires de France, Paris, 1978, $2^{\text {a }}$ parte, "Essai sur le don. Forme et raison de l'échange...", pp. 145 ss.

37 Véase José Manuel Pedrosa, Bestiario. Antropología y simbolismo animal, Grupo Medusa Ediciones, Madrid, 2002, pp. 193-199.

38 Véanse P. SÉbillot, Légendes..., p. 208 y 334; M. Chevalier, Tipos cómicos..., p. 104.

${ }^{39}$ Véase Willard F. King, Juan Ruiz de Alarcón, letrado y dramaturgo. Su mundo mexicano y español, El Colegio de México, México, 1989, pp. 167-171, 
Además, es posible que la mención de "Tordesillas" -sin tener que buscar una alusión al autor del Quijote apócrifo, como lo dicen algunos críticos- prolongue los juegos verbales a los cuales acabamos de referirnos. Efectivamente, no hay que olvidar la afición de los españoles del siglo xviI por la paronomasia, según lo indicado por Correas en su Vocabulario:

...en la lengua española, usamos mucho la figura "paronomasia", que es semejanza de un nombre a otro, porque para dar gracia con la alusión y ambigüedad a lo que decimos, nos contentamos y nos basta parecerse en algo un nombre a otro para usarlo por él... ${ }^{40}$

Es lo que Cervantes había ilustrado abundantemente en el Quijote $^{41}$. ¿No se tratará aquí de sugerir festivamente que Tordesillas es la ciudad de los tordos, de esas avecillas habladoras, como lo indica Covarrubias, en la entrada "Tordo" de su Tesoro: "Esta avecica tiene la lengua harpada y por eso imita la voz humana"42? De ahí que el refrán "Charlar como tordos en campanario", signifique hablar mucho y de manera inconsiderada. Podría ser ésta una manera de subrayar todavía más la paradoja entre la aguda sentencia apuntada por el zapatero y lo que él representa como hablador, semejante a un tordo, tanto más que su tienda es un lugar de sociabilidad en que corren las hablillas.

Por fin, hay que recordar que muchos remendones (tanto zapateros como sastres) tenían fama de ser cristianos nuevos ${ }^{43}$. ¿Habrá alguna jocosa intención en esa manera de ostentar "Castilla la Vieja"?

Sea lo que fuere, la divertida incongruencia que existe entre el escueto aforismo y la extensión de la firma y vileza del autor bien llama la atención de los peregrinos. Si bien, en un primer

185-186, 247 ss. Recuérdese que a Alarcón se le llamaba Corcova y Corcovilla, lo que ocasionó en particular un enfrentamiento entre él y Quevedo.

40 Se trata de un comentario de Correas al refrán: "Al buen callar, llaman Sancho; al bueno bueno, Sancho Martínez" (Vocabulario de refranes...). Asimismo, el paremiólogo vuelve sobre dicha figura en su comentario al proverbio "Al mal uso, quebralle la güeca".

${ }^{41}$ Sobre el particular véase A. REDondo, Otra manera de leer el "Quijote"..., y más directamente, pp. 242-243.

42 Tesoro..., p. 967b.

43 Véanse Julio Caro Baroja, Los judios en la España moderna y contemporánea, Istmo, Madrid, 1978, t. 2, pp. 15-16; Antonio Domínguez Ortiz, Los juedoconversos en España y América, Istmo, Madrid, 1958, pp. 202-203. 
tiempo, Antonio se contenta con resaltar el aspecto formal de esa incongruencia, más adelante, cuando ya están caminando, no dejan de reírse de la firma del zapatero y de lo que implica. No por nada es el Persiles un "libro de entretenimiento" 4 .

Pero tiempo es ya de hablar del colector de las máximas, de ese "peregrino de los aforismos".

Nótese que ese "gallardo" romero se califica él mismo de "peregrino" y de "hombre curioso", indicando que sobre la mitad de su alma predomina Marte, y sobre la otra mitad, Apolo y Mercurio (p. 631). No se trata pues de una evocación a lo Garcilaso de las Armas y las Letras, que estaría relacionada con el gran debate sobre el particular tal como aparece por ejemplo en el Quijote, ya que aquí figura otro elemento, vinculado a Mercurio. No hay que perder de vista que Mercurio es el dios de los comerciantes y de los ladrones, pero asimismo es el mensajero de los dioses, de manera que viene a ser el protector de los viajeros. La primera de las características conviene particularmente a un hombre que ha sido soldado -según lo que dice-, alcanzando alguna nombradía. La segunda particularidad, la que está unida a Apolo, encaja con su estatus de hombre de letras (ha publicado algunos libros) y con sus pretensiones literarias: de ahí que lleve unas escribanías sobre el brazo izquierdo y un cartapacio en la mano (pp. 630-631). Por fin, la tercera peculiaridad lo define asimismo muy bien pues quiere comerciar con el privilegio de imprenta (piensa ganar con él dos mil ducados por lo menos, lo que es un guiño irónico hecho al lector pues la cantidad es enorme). Además, piensa imprimir lo que ha "robado" a los demás pues el libro lo constituye "a costa ajena". Por ello el patronato de Mercurio le corresponde perfectamente y también porque es un viandante, un peregrino.

Es posible ver en este personaje una proyección irónica del autor, antiguo soldado, literato y viajero, quien tomaría un distanciamiento muy cervantino y burlesco con relación a sí mismo, sobre todo si, según lo adelantado por Ruffinatto, Cervantes tenía intención de publicar un libro de aforismos ${ }^{45}$. Muy

44 Véase Augustin Redondo, "El Persiles, «libro de entretenimiento" peregrino", en Peregrinamente peregrinos. Actas del V Congreso Internacional de la Asociación de Cervantistas, ed. Alicia Villar Lecumberri, Asociación de Cervantistas, Alcalá de Henares, 2004, t. 1, pp. 67-102.

45 Véase Miguel de Cervantes, Flor de aforismos peregrinos, ed. A. Ruffinatto, Edhasa, Madrid, 1995, prólogo, pp. 9-20. 
cervantino asimismo es ese juego con los diversos autores del libro que desea publicar, en la línea del Quijote, y también esa ironía manifestada acerca de la materia utilizada, la de los aforismos, ya muy de moda, pero muchas veces "robada" a otros autores.

Pero cabe presentar otra hipótesis y ver en este personaje una evocación literaria de Antonio Pérez. En efecto, éste, que fue un hombre gallardo, fue también el primero en dar a la imprenta una colección de aforismos en lengua castellana. Como es sabido, fue el antiguo Secretario de Felipe II (lo de las escribanías y el cartapacio serían emblemáticos de su oficio). Antonio Pérez se había enemistado con el soberano español por haber desempeñado un papel activo en la muerte de otro secretario, Escobedo, de quien decía que favorecía los proyectos reales de su señor, el brillante don Juan de Austria, hermanastro del monarca.

Después de los disturbios en Aragón, tierra donde, al ser perseguido por el monarca, Pérez se había refugiado, y de la acción inquisitorial contra él, tuvo que fugarse a Navarra de Francia en 1591. Pasó luego a Inglaterra y posteriormente volvió a Francia, viajando, peregrinando, de tal modo, entre varios lugares y varios países ${ }^{46}$. Aparece pues como un viator, un peregrino ${ }^{47}$. La primera obra que publica, una relación de los

46 Sobre Antonio Pérez, véanse Cesáreo Fernández Duro, Antonio Pérez en Inglaterra y Francia (1591-1612), Imprenta P. Tello, Madrid, 1890; José Ignacio Tellechea Idígoras, "Antonio Pérez, a través de la Nunciatura de Madrid”, Anthologica Annua, 5 (1957), pp. 653-682; Gregorio Marañón, Antonio Pérez (el hombre, el drama, la época), Espasa Calpe, Madrid, 1958, 2 ts.; Antonio Pérez Gómez, Antonio Pérez, escritor y hombre de estado, "...la fonte que mana y corre...", Cieza, 1959; Gustav Ungerer, A Spaniard in Elisabethan England. The correspondance of Antonio Pérez's exile, Tamesis, London, 1975, 2 ts. Además, véase la tesis de Modesto Santos López, Filosofía y política en la obra de Antonio Pérez, Secretario de Felipe II, Universidad Complutense de Madrid, 1988; véase asimismo la tesis y el trabajo de habilitación de Paloma Bravo, Contribution à une étude de la "légende noire": les "relaciones" d’Antonio Pérez (édition critique et commentée de "Un pedaço de Historia..."), Université de la Sorbonne Nouvelle, Paris, 1994; Les aphorismes politiques en Espagne au tournant des XVI et XVII ${ }^{e}$ siècles (édition des "Aphorismes" d’Antonio Pérez), Université de la Sorbonne Nouvelle, Paris, 2003. Véanse también los diversos artículos de esta autora vinculados al Secretario de Felipe II.

${ }^{47}$ Nótese que en las primeras cartas castellanas, Cartas de Antonio Pérez, Secretario de Estado que fue del Rey Cathólico, Don Phelippe II... de hacia 1600 (BNE: R. 8202; véase nota siguiente) figura una carta del antiguo Secretario dirigida a su mujer, doña Juana Coello, y en ella dice: "Dévele aver parescido 
sucesos de Aragón, sale en Pau en 1591 y luego, aumentada, en León de Francia -según parece-, en 1593. Lleva un título muy revelador: Pedaços de historia o Relaciones assý llamadas por sus Auctores los Peregrinos ${ }^{48}$. Él mismo, distanciándose de sí, adopta varias máscaras como lo hará el autor del Quijote. Así figura bajo el nombre de Rafael Peregrino, al dirigirse al impresor de los Pedazos ${ }^{49}$, y también ha de adoptar el seudónimo de $\mathrm{El} \mathrm{Cu}$ rioso ${ }^{50}$. Adviértase de paso que Rafael es, en cierto modo, un

a V.M. que yo he peregrinado por jardines o reposado en camas de flores. Y digo que no he hecho otra cosa que andar de puerta en puerta pidiendo el pan..." (f. $3 \mathrm{v}^{\circ}$ ).

48 Hemos utilizado un ejemplar de la segunda edición, la de 1593: Pedaços de Historia o Relaçiones assý llamadas por sus Auctores los Peregrinos. Se presenta la obra como impresa en León (BNE: R. 5047). No obstante, la bibliografía de las obras de Antonio Pérez no queda nada clara. Según Gustav Ungerer, la impresión se hubiera realizado en Inglaterra, costeada por el Conde de Esex (favorito de la soberana Isabel II), con el cual Antonio Pérez tuvo, en ese país, cordiales relaciones (cf. A. Pérez Gómez, Antonio Pérez, pp. 76-77). Y bien es verdad que el libro, compuesto de cuatro relaciones vinculadas a la historia de Antonio Pérez y a las persecuciones sufridas por él, va dedicado "Al Illustrísimo Señor El Conde de Essex" por Raphael Peregrino. Lo cierto, a pesar de todo, es que, en el ejemplar de sus Aphorismos de las Cartas españolas y latinas, impresos en París (sin ninguna indicación suplementaria) y encuadernado con sus primeras cartas castellanas, Cartas de Antonio Pérez, Secretario de Estado que fue del Rey Cathólico Don Phelippe II de este nombre. Para diversas personas después de su salida de España, impresas también en París, sin fecha, pero de hacia 1600 (BNE: R. 8202), figura al final del conjunto, dentro de la misma encuadernación, una carta autógrafa de Antonio Pérez, fechada en Saumur a 12 de febrero de 1593, dirigida a Roland Dujardin, Seigneur des Roches, en Tours, en que le ofrece un ejemplar de su obra, sin más especificación. ¿Se tratará de los Pedaços de Historia...? El conjunto constituye un ex-libris de Roland Dujardin.

49 En el título de los Pedaços... indica Pérez que los textos son de varios autores, los Peregrinos. El primer preliminar es una carta al impresor que lleva por título: "Raphael Peregrino al Impressor". En ella, se refiere a los autores: frente a Raphael Peregrino, estaría su hermano gemelo Azarías Peregrino; por ello, el estilo de las relaciones "paresce el lenguaje de uno". Alude además varias veces a la Curiosidad del impresor y de los lectores, ya que, los textos van destinados a los curiosos. La dedicatoria que sigue para el Conde de Esex, va firmada de Raphael Peregrino. En ella, se refiere a los Peregrinos, a su peregrinación en Inglaterra, exaltando las cualidades del Conde, en particular la Prudencia, con una óptica tacitista. En otros textos que siguen, aparece varias veces Rafael Peregrino y asimismo el impresor dice que ha recibido los papeles impresos "por medio de un Curioso".

50 Por ejemplo, en las Cartas de Antonio Pérez..., de hacia 1660 (BNE: R. 8202), ya citadas en la nota 47, después de las cartas y de los aforismos, aparece "El Curioso a Todos", en que se encuentra el texto siguiente, con una 
intensivo de Peregrino, ya que, según la Biblia, el Arcángel había servido de guía al joven Tobías, en sus largas jornadas. No obstante, Antonio Pérez revela asimismo que era muy devoto de dicho Arcángel ${ }^{51}$.

Por otra parte, el antiguo Secretario de Felipe II publicó unos cuantos volúmenes de relaciones y cartas diversas cuando estaba en Inglaterra y Francia, sacando de ellas (en particular de las epístolas latinas y castellanas, pero también de las relaciones) varias series de aforismos, de orientación tacitis$\mathrm{ta}^{52}$, que ven la luz entre 1600-1601 y 1603, bajo el nombre de Raphael Peregrino o El Curioso ${ }^{53}$. Van a gozar fuera de España

alusión a Justo Lipsio: "No piensen que es del Auctor de las Cartas este stylo [de los aforismos], sino de quien le ha querido imitar, como Justo Lypsio a Cornelio Tácito en los Breviarios de cada libro..." En las Segundas Cartas de Antonio Pérez. Más los Aphorismos dellas sacados por el Curioso que sacó los de las Primeras (Francisco Huby, Paris, 1603, BNE: R.14325), indica, bajo el título: "El Curioso a Todos": "No les parezca, Señores, que he callado mucho para curioso, que de curiosos es callar por aprender, y aún de discretos..." (f. 2r). Véase también lo indicado en la nota precedente.

${ }^{51}$ El hijo segundo de Antonio Pérez se llamaba Antonio Raphael. Le dirige una carta, firmada Raphael Peregrino, en que le reprocha el utilizar sólo el primer nombre, añadiendo: "No quiero que olvidéys el nombre de Raphael que le estimo yo en mucho y os lo di por devoción del Señor San Raphael" (la carta figura entre las que se publican hacia 1600 (BNE: R 8202, f. 9r).

${ }^{52}$ Indica en la dedicatoria de los Aphorismos de las Cartas españolas y latinas, que siguen a las primeras cartas castellanas de hacia 1600 (BNE: R. 8202), la intención que ha sido la suya y la tonalidad tacitista que tienen dichos aforismos: véase el texto que corresponde a la nota 56 . Últimamente, además de la ed. de Paloma Bravo, sin publicar (cf. supra, nota 46), ha salido una edición completa de los aforismos: Antonio Pérez, Aforismos de las cartas y relaciones, eds. A. Herrán Santiago y M. Santos López, Larumbe, Zaragoza, 2009. La que publicó Alfredo Alvar Ezquerra, Relaciones y cartas, Turner, Madrid, 1986, 2 ts. no encierra todos los aforismos.

53 Véase supra notas 48-50. Obsérvese que en una de las Segundas cartas... de 1603 (BNE: R. 14325) dirigida "A un amigo", ya asume la unidad de las autorías múltiples pues escribe: "Pregúntame sy algunas cartas que andan entre las impressas con nombre de otros son en realidad de verdad mías o de aquellos: porque el stylo, según V.S. dize, quienquiera que leyere las unas y las otras con un poco de atençión, no le juzgará differente, como si una persona vestida de máscara, por mucho que se quiera disfrazar, podrá ser conosçido en el ayre natural. Yo diré francamente la verdad... Señor todas quantas cartas andan en nombre de otros con las mías son dessa mi pluma grossera tal qual, la que me cupo por suerte. Lo mismo digo de cuanto anda en el libro de las Relaçiones, o sea debaxo del nombre del Curioso, o de qualquier otro... En fin todo quanto anda impresso en aquellos scriptos míos, mío es" (carta CXXIX, f. 228r-v). 
-por razones obvias- de múltiples ediciones que dieron fama al autor (el cual fue muy apreciado, en particular por Baltasar Gracián). En Francia, traducidos, se publicaron con el nombre de Sentences dorées ${ }^{54}$, recuerdo probablemente de las famosas Epîtres dorées -así se las llamó en el país galo- de Antonio de Guevara, las cuales encerraban muchas sentencias que aparecen en los márgenes de sus Epístolas familiares (1539-1541) ${ }^{55}$.

Estos aforismos fueron el punto de partida de los que en 1614 publica su amigo Álamos de Barrientos.

Si bien Antonio Pérez, el autor de los aforismos, es el Peregrino, también es un hombre "curioso" (ya lo hemos visto), como el personaje del Persiles. Efectivamente, en el proceso de duplicación que ha adoptado, el antiguo Secretario finge que las relaciones salen de unos papeles dados por "un curioso de estos tiempos" y, bajo el título "A la curiosidad, un curioso devoto", subraya el proceso de elaboración de los aforismos:

He querido ofresçer a la Curiosidad, por ser uno de los suyos, el trabajo que he tomado en sacar los Aphorismos de las Cartas Españolas y Latinas de Antonio Pérez. Llámolos assí a imitaçión del Bitonto que esprimió y destiló a Cornelio Tácito por entretenimiento y curiosidad suya entre sus mayores y diferentes estudios. Papel que él intituló Aphorismos de Cornelio Táçito. Hóvele a las manos de un muy curioso... ${ }^{56}$

O sea que es como si sus aforismos salieran de otros escritos (en realidad de sus propias cartas), a lo cual hay que añadir que se le achacaba el que parte de su obra utilizara secretos de Estado "robados" a Felipe II, es decir que fuera de "otro" autor.

Tampoco hay que dejar de lado la imagen que aparece en el título inserto en el Persiles: "Flor de los aforismos...", dado que

54 Véase Aphorismes ou Sentences dorées extraictes des lettres tant Espagnoles que Latines d'Anthoine Peres... Faictes francoises par Jacques Gaultier, Pierre Chevallier, Paris, 1602 (un ejemplar en la BNF).

55 Alonso Enríquez de Guzmán recoge bastantes sentencias de los márgenes de las Epistolas familiares de Guevara y las presenta al príncipe Felipe (el que será Felipe II), sin mencionar la fuente, como si vinieran de su cosecha, con el fin de orientar el comportamiento privado y público del futuro soberano. Sobre el particular, véase Augustin Redondo, "Une source du Libro de la vida y costumbres de don Alonso Enríquez de Guzmán: les Epistolas familiares d'Antonio de Guevara”, BHi, 71 (1969), pp. 174-190.

56 Véase Aphorismos de las Cartas españolas y latinas, de hacia 1600, impresos en París (BNE: R. 8202), f. 2r-v. 
Pérez escribía que, con sus aforismos, trataba de hacer como "con las hiervas y flores, las mejores a la vista y olfacto, destiladas y esprimidas, dan lo bueno que tienen para el uso y benefiçio humano" 57 .

Por fin, al Secretario se le había considerado en España como un traidor y hasta había corrido la voz, cuando estaba en Navarra, que el rey de Francia iba a suministrarle soldados para que pudiera invadir el reino de Aragón (ésta sería la alusión a Marte $)^{58}$. Sin embargo, hacia el final de su vida, las cosas iban cambiando. En 1611, intentaba negociar su vuelta a España, cuando le sorprendió la muerte. Su hijo conseguiría su rehabilitación poco después, en 1615.

Por otra parte, hay que valorar el juego constante en la obra del antiguo Secretario entre las diversas autorías, juego muy cervantino, que no podía sino complacer al autor del Quijote, aunque Cervantes también se distanciara irónicamente del personaje creado en el Persiles.

Todo parece pues indicar que el "Peregrino de los aforismos" es una reelaboración literaria del personaje histórico de Antonio Pérez ${ }^{59}$, el cual había reunido aforismos tacitistas sobre el arte de gobernar, pero también sobre temas muy diversos, en particular sobre los que figuran en el Persiles.

El episodio que se acaba de examinar pone de relieve que el Persiles es, en primer lugar, un "libro de entretenimiento". Con una orientación lúdica, el autor elabora el relato a partir de una intertextualidad amplia que abarca tanto diversas tradiciones culturales como el contexto histórico más inmediato.

57 Ibid., f. 2 r.

58 Acerca de los diversos intentos de invasión de Aragón, relacionados con Antonio Pérez, véase G. Marañón, Antonio Pérez, t. 2, pp. 623 ss. El espía Pascual de Santisteban decía del antiguo Secretario de Estado: "es un mal hombre, traidor a su Rey natural” (t. 2, p. 633).

${ }^{59}$ En 2001 ha salido la traducción francesa de las obras de ficción en prosa de Cervantes dirigida por Jean Canavaggio (Gallimard, Paris). JeanMarc Pelorson, que se ocupó de traducir y comentar el Persiles, ha sugerido en una nota (II, pp. 1020-1021, n. 4) que Cervantes pudo inspirarse en Antonio Pérez para crear al personaje de Clodio, el maldiciente. Nótese además que Gustav Ungerer pensaba que Shakespeare se había servido de Antonio Pérez para elaborar, en Love's labour's lost, al personaje de Armado, el militar burlesco (Gustav Ungerer, Anglo-Spanish relations in Tudor Literature, Ams Press, New York, 1956, p. 152). 
Por ello, para poder disfrutar plenamente de la lectura de un texto repleto de sugerencias y sentido, el receptor ha de leer a varias luces, único modo de adentrarse verdaderamente en dicho texto.

Augustin Redondo Université de la Sorbonne Nouvelle-CRES 